\title{
Comparative Analysis on Insulation Performance of Traction Motors for Hybrid Vehicles
}

\author{
최수연 ${ }^{1}$, 박찬용 ${ }^{1}$, 김성욱 ${ }^{1}$, 박대원 $^{1}$, 길경석 ${ }^{1, a}$, 이강원 $^{2}$
}

(Su-Yeon Choi ${ }^{1}$, Chan-Yong Park', Sung-Wook Kim¹, Dae-Won Park', Gyung-Suk Kil ${ }^{1, a}$, and Kang-Won Lee ${ }^{2}$ )

\begin{abstract}
The object of this paper is to acquire the data related to insulation evaluation of hybrid vehicle traction motors. We made a comparative analysis on Insulation Resistance(IR), Dielectric Absorption Ratio (DAR), and Polarization Index (PI) of the motor stators. The experiment was carried out according to IEEE Std. 43 and IEC $60085^{-1}$ for insulation resistance test standard of rotating machinery. Test voltage of $500 \mathrm{~V}$ was applied between a phase and the enclosure. The IR and the DAR of used motors were lower than those of new ones. The DAR and the PI were $0.92 \sim 1.02$ and $0.74 \sim 1.1$, respectively and the result did not meet the recommendation basis 2 for insulation level $\mathrm{H}$. From the experimental results, we could prepare parameters and basis for insulation evaluation of the traction motor stator by the comparative analysis of short-time insulation resistance changes, DAR and PI.
\end{abstract}

Key Words : Hybrid vehicle, Traction motor, Insulation performance, Insulation resistance (IR), Dielectric absorption ratio (DAR), Polarization index (PI)

\section{1. 서 론}

화석연료의 고갈에 따른 고유가 현상과 환경오 염의 문제로 하이브리드 차량에 대한 관심이 증대 되고 있으며 국내에서도 하이브리드 차량에 대한 연구가 활발히 이루어지고 있다. 하이브리드 차량 은 내연기관과 전기에너지를 동시에 사용하는 것 으로 유도전동기가 차량의 주요 동력원으로 사용 되고 있다. 그러나 전기철도나 하이브리드 자동차 와 같은 전기자동차에서 사용되는 유도전동기 즉, 견인전동기는 빈번한 기동과 정지, 진동과 같은 열 악한 환경에 노출되어 있어 운전상태의 고신뢰성 이 요구된다[1].

최근 IGBT(Insulated Gate Bipolar Transistor)

1. 한국해양대학교 전기전자공학부

(부산시 영도구 동삼동 1)

2. 한국철도기술연구원 바이모달수송시스템연구단

a. Corresponding Author : kilgs@hhu.ac.kr

접수일자 : 2008. 11. 10

1차 심사 : 2008. 11. 19

심사완료 : 2008. 11. 24
나 $\mathrm{FET}$ (Field Effect Transistor)와 같은 전력용 반도체 소자의 진보와 각종 제어기술의 발달에 따 라 유도전동기의 고효율 운전이 가능해졌으며, 가 변속 제어성능이 크게 향상되었다. 그러나 전력용 반도체 소자의 고속스위칭 동작에 의해 $600 \mathrm{~V}$ 이 하의 저압 유도전동기의 운전시에도 $\mu \mathrm{s}$ 이하의 상 승시간당 최고 수 천 $\mathrm{V}$ 의 과도전압이 발생할 수 있으며 전동기 권선에 불규칙적인 전압분포를 야 기시켜 최종적으로 유도전동기의 절연파괴를 초래 할 수 있다[2-5]. 또한 유도전동기의 제조시 결함 이나 고온, 흡습 등 운전환경에 의해 절연열화가 진행되고 설계시 기대수명을 갖지 못하므로 기기 의 신뢰성이 저하된다. 절연은 기기의 수명과 직접 적인 관련이 있으며 이러한 절연성능을 평가하기 위해서는 기기에 대한 정확한 절연열화기구를 이 해하고 상황에 가장 적합한 절연평가방법을 적용 해야 한다. 현재까지의 절연시험법은 절연저항시 험, 직류전류시험, 교류전류시험, 유전정접시험, 부 분방전시험 등이 있으며 그 중 절연저항시험은 다 른 절연시험과 비교해 흡습이나 오손 등의 결함에 
의한 절연저항 저하의 유무를 진단하고, 절연상태 의 추정에 사용되고 있다[6-11].

절연저항시험은 절연저항계를 이용하기 때문에 측정이 용이하며, 시험전압이 낮고 측정법이 간단 하기 때문에 일반적으로 많이 이용되고 있다. 본 논문에서는 정격전압 $400 \mathrm{~V}$, 절연등급 $\mathrm{H}$ 종인 하이 브리드 차량용 견인전동기를 대상으로 절연저항 (Insulation Resistance, IR), 성극지수(Polarization Index, PI) 및 유전흡수율(Dielectric Absorption Ratio, DAR)을 측정하였으며 IEEE Std. 43과 IEC 60085-1 규격에 대하여 기사용 전동기와 신품 전 동기에서 측정된 결과를 비교하여 절연성능을 평 가하였다.

\section{2. 절연평가방법}

절연저항은 피시험체인 전동기의 권선과 외함에 직류전압을 인가하여 누설전류를 측정함으로써 산 출된다. 인가되는 시험전압은 표 1 과 같이 피시험 체의 정격전압에 따라 달라지며 피시험체의 전기 적인 사양을 파악하는 것이 중요하다.

표 1. 절연저항시험시 인가전압.

Table 1. DC voltage to be applied during IR test.

\begin{tabular}{|c|c|}
\hline $\begin{array}{c}\text { Winding rated } \\
\text { voltage }[\mathrm{V}]\end{array}$ & $\begin{array}{c}\text { Insulation resistance test dc } \\
\text { voltage [V] }\end{array}$ \\
\hline \hline$<1,000$ & 500 \\
\hline $1,000-2,500$ & $500-1,000$ \\
\hline $2,501-5,000$ & $1,000-2,500$ \\
\hline $5,001-12,000$ & $2,500-5,000$ \\
\hline$>12,000$ & $5,000-10,000$ \\
\hline
\end{tabular}

절연저항 $I R$ 은 시험전압 $E$ 와 누설전류 $I_{l e a k}$ 로 나 타낼 수 있으며 식 (1)과 같다.

$$
I R=\frac{E}{I_{\text {leak }}}[\Omega]
$$

그러나 누설전류의 크기는 시료의 형태와 크기에 따라 달라지며 시간에 따라 변하기 때문에 단편적 인 절연저항의 크기만으로는 절연상태를 판단하기 어렵다. 그림 1 과 같이 고체상태의 절연체가 건전 한 상태에서는 누설전류가 극히 미소하며 흡수전 류가 감소하기 때문에 절연저항은 시간에 따라 초기에는 급격히 상승하고 시간에 따라 증가하지
만 열화 또는 오손된 상태에서는 시간에 따른 절 연저항의 상승비율이 급격히 감소하게 된다.

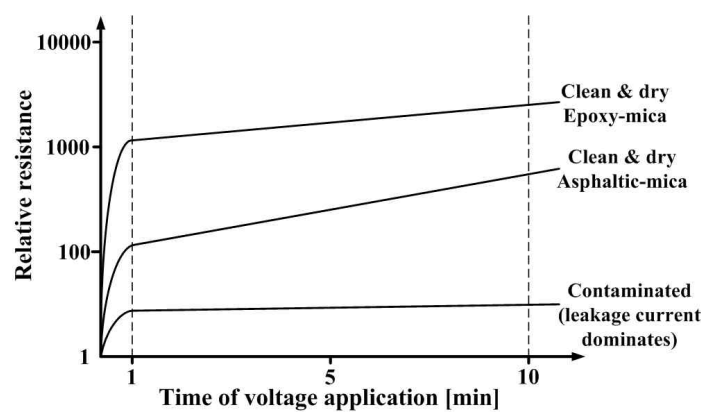

그림 1. 전압인가시간에 따른 절연저항의 변화.

Fig. 1. Changes of insulation resistance as a function of voltage application time.

이러한 누설전류 또는 절연저항의 시간변화를 나 타내는 지표로서 유전흡수율과 성극지수가 사용되 며 이를 이용하여 절연물의 상태를 판정한다.

유전흡수율은 $t_{1}$ 후의 절연저항 $I R_{t 1}$ 과 $t_{2}$ 후의 절 연저항 $I R_{t 2}$ 의 비로서 식 (2)와 같이 나타낼 수 있다.

$$
D A R=\frac{I R_{t 2}}{I R_{t 1}}
$$

건전한 절연물에서 흡수전류는 그림 2 와 같이 시험전압 인가 후 $2 \sim 3$ 분 동안 감소하므로 절연저 항은 증가하며 유전흡수율이 1 이상이면 절연상태 가 양호한 것으로 판단할 수 있다[12].

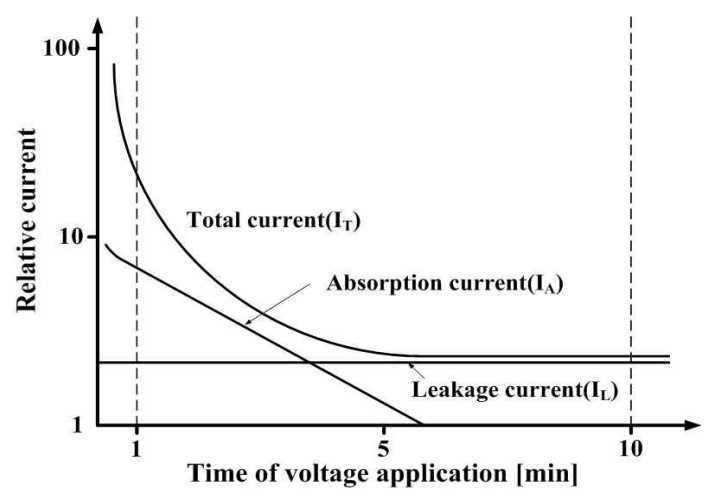

그림 2. 절연물에 흐르는 전류의 종류.

Fig. 2. Types of currents in insulation materials. 
성극지수는 1 분 후의 절연저항 $I R_{1 \min }$ 과 10 분 후의 절연저항 $I R_{10 \mathrm{~min}}$ 의 비로서 식 (3)과 같이 나타 낼 수 있으며 IEC 60085-1에서는 절연등급에 따른 최소 성극지수를 표 2와 같이 권장하고 있다[13].

$$
P I=\frac{I R_{10 \min }}{I R_{1 \min }}
$$

표 2. 최소 권장 성극지수.

Table 2. Recommendation minimum PI value.

\begin{tabular}{|c|c|}
\hline Thermal class & Minimum polarization index \\
\hline \hline Class A & 1.5 \\
\hline Class B & 2.0 \\
\hline Class F & 2.0 \\
\hline Class H & 2.0 \\
\hline
\end{tabular}

\section{3. 측정 및 분석}

본 논문에서는 하이브리드 차량용 견인전동기의 고정자권선의 절연상태를 평가하기 위하여 기사용 품과 신품을 대상으로 절연저항 및 성극지수를 측 정, 분석하였다. 측정에 사용된 견인전동기의 사양 은 표 3 과 같다.

표 3. 견인전동기의 사양.

Table 3. Specification of the traction motor.

\begin{tabular}{|c||c|}
\hline 형 식 & 3상 6극 유도전동기 \\
\hline 절연등급 & $\mathrm{H}$ 종 \\
\hline 직류링크전압 & $480 \mathrm{~V}$ \\
\hline 정격전압/전류 & $400 \mathrm{~V} / 82.7 \mathrm{~A}$ \\
\hline
\end{tabular}

견인전동기의 정격전압이 $400 \mathrm{~V}$ 이므로 $\mathrm{IEEE}$ Std. 43에 의거하여 기사용 전동기와 신품 전동기 의 각 상 $(\mathrm{U}, \mathrm{V}, \mathrm{W})$ 과 외함에 시험전압 $500 \mathrm{~V}$ 를 인가하여 절연저항을 측정하였다. 측정결과를 그림 3에 나타내었다.

절연저항의 측정결과, 기사용 전동기에서는 20 0 300 M $\Omega$ 정도로 신품 전동기에 비해 전체적으 로 낮은 절연저항을 나타내었으며 10 분 동안 절연

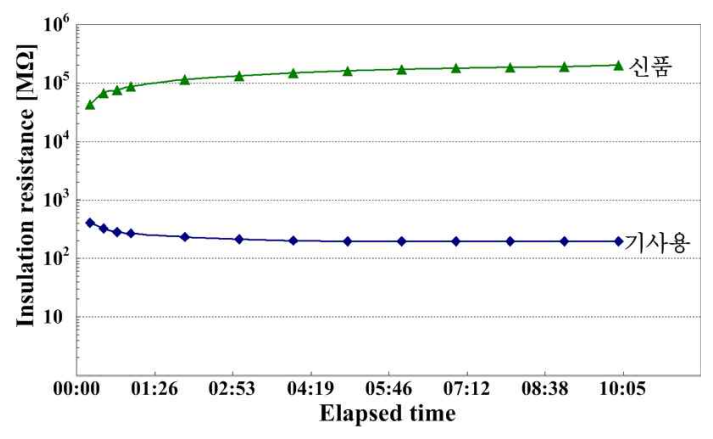

(a) U상-외함

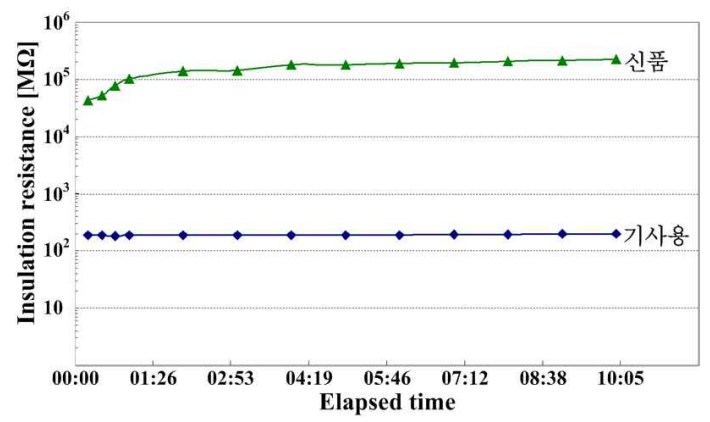

(b) $\mathrm{V}$ 상-외함

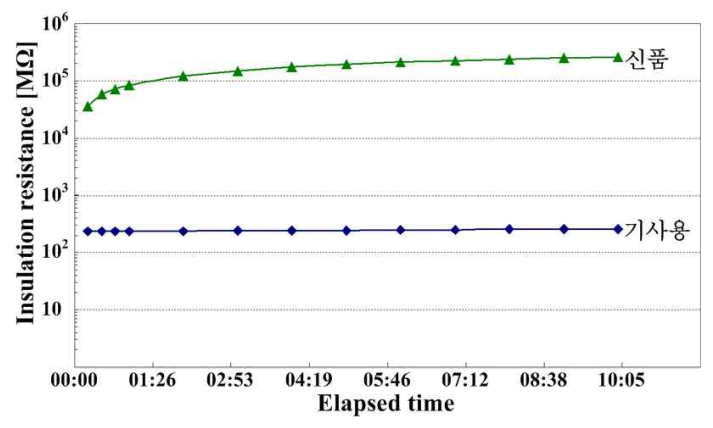

(c) $\mathrm{W}$ 상-외함

그림 3. 절연저항의 측정결과.

Fig. 3. Measurement result of IR.

저항이 감소 또는 유지하였으나 신품 전동기에서 는 기사용 전동기에 비해 높은 절연저항이 나타났 으며 인가시간동안 절연저항이 증가하는 추세를 나타내었다. 유전흡수율의 측정은 시험전압인가 후 30 초 후와 3 분 후의 절연저항을 이용하였으며 기 사용 전동기와 신품 전동기에서의 측정결과를 그 림 4에 나타내었다.

유전흡수율은 기사용 전동기의 U상에서는 0.92, $\mathrm{V}, \mathrm{W}$ 상에서는 각각 $1.01,1.02$ 로 측정되었으며 신 품 전동기에서는 $\mathrm{U}, \mathrm{V}, \mathrm{W}$ 에서 $1.17,1.03,1.22$ 로 


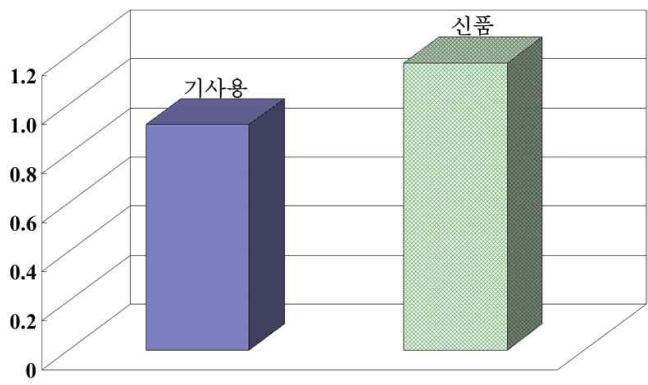

(a) U상-외함

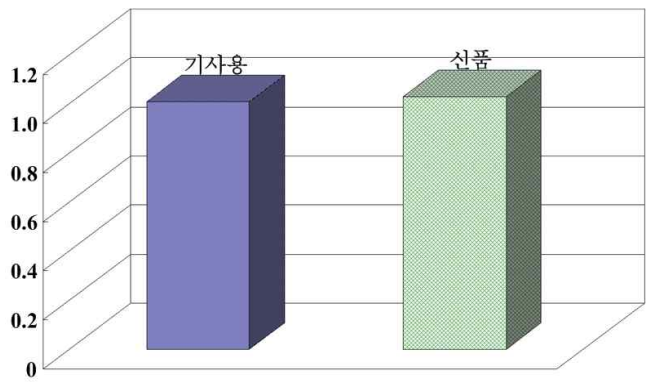

(b) $\mathrm{V}$ 상-외함

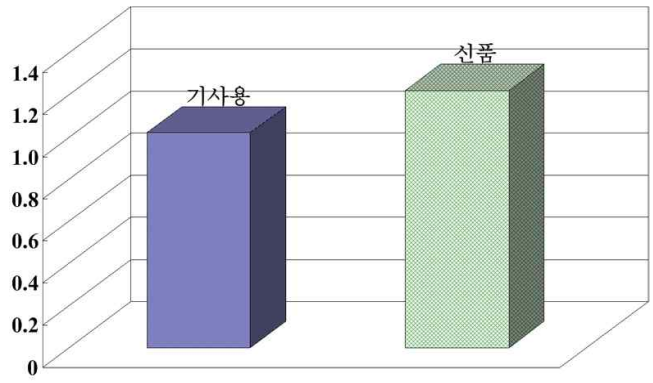

(c) $\mathrm{W}$ 상-외함

그림 4. 유전흡수율의 측정결과.

Fig. 4. Measurement result of DAR.

측정되었다. 유전흡수율의 측정결과, 기사용 전동 기에서는 1 이하 또는 1 정도의 값으로 흡수전류가 감소하지 않고 유지 또는 증가하는 것으로 나타났 으며 신품 전동기에서는 전체적으로 흡수전류가 감소하는 추세를 나타내었다.

또한 성극지수를 측정하여 절연저항의 시간변화 및 유전흡수율과 비교하였으며 IEC 60085-1에 제시 된 절연등급별 권장기준를 이용하여 절연상태를 평 가하였다[13]. 성극지수의 측정결과는 그림 5 와 같다.

성극지수의 측정결과, 기사용 전동기에서는 $\mathrm{U}$, $\mathrm{V}, \mathrm{W}$ 상에서 각각 $0.74,1.08,1.1$ 로 IEC 60085-1 에 제시된 최소 권장기준에 미달하는 결과를 나타

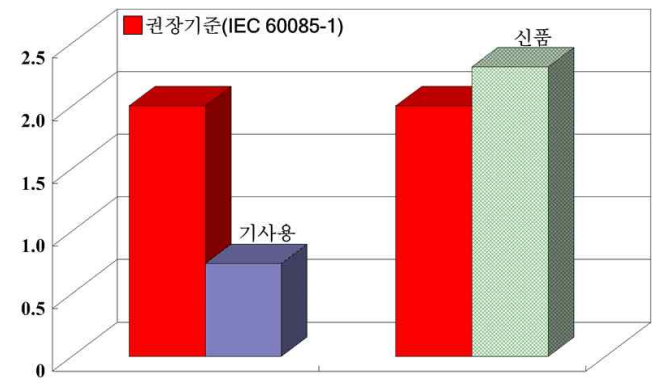

(a) U상-외함

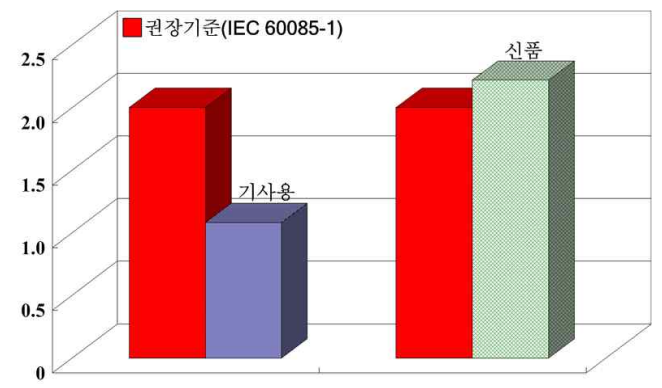

(b) $\mathrm{V}$ 상-외함

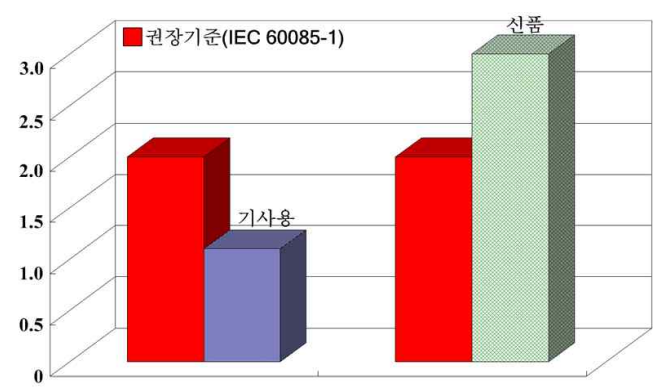

(c) $\mathrm{W}$ 상-외함

그림 5. 성극지수의 측정결과.

Fig. 5. Measurement result of PI.

냈으며 신품 전동기에서는 $\mathrm{U}, \mathrm{V}, \mathrm{W}$ 상에서 2.31, $2.22,3$ 으로 2 이상의 성극지수가 측정되어 절연상 태가 양호한 것으로 나타났다.

\section{4. 결 론}

본 논문에서는 하이브리드 차량용 견인전동기의 절연성능평가기준을 마련하기 위해 기사용 및 신 품 전동기를 대상으로 시간에 따른 절연저항의 변 화와 유전흡수율, 성극지수를 측정하고 그 결과를 비교하였다. 실험은 절연저항시험 규격인 $\mathrm{IEEE}$ 
Std. 43 및 IEC 60085-1에 따라 각 상과 외함간에 시험전압 $500 \mathrm{~V}$ 를 인가하여 수행하였다. 시간에 따른 절연저항의 변화를 측정한 결과, 기사용 전동 기에서는 200 300 M 2 정도로 측정되었으며 신품 전동기에서는 수 백 $\mathrm{G} \Omega$ 의 높은 절연저항이 측정 되었다. 그러나 절연저항은 피시험체의 크기나 구 조에 따라 다르게 나타나므로 단순히 측정시점에 서 나타난 절연저항의 크기만으로는 절연상태를 평가하기 어렵다. 따라서 시간에 따른 절연저항의 변화 및 유전흡수율과 성극지수를 측정함으로써 전동기의 절연상태를 평가하였다.

유전흡수율은 절연체에서 흡수전류의 감소비율 을 측정하는 것으로 기사용 전동기에서 $0.92 \sim 1.02$, 신품 전동기에서 $1.22 \sim 1.36$ 으로 측정되어 기사용 전동기에서 흡수전류의 감소비율이 낮은 것으로 나타났으며, 성극지수에서도 기사용 전동기는 0.7 4 1.1로 측정되어 IEC 60085-1에 제시된 권장 성 극지수에 미달하였지만 신품 전동기에서는 2.22 3 으로 권장기준을 만족하는 결과를 나타내었다. 절 연저항의 시간변화, 유전흡수율 및 성극지수를 측 정함으로써 하이브리드 차량용 견인전동기의 절연 성능을 평가할 수 있었다. 현재 시행되고 있는 전 동기의 성능시험이나 절연평가에서도 단순 절연저 항의 측정 외에 절연저항의 시간변화, 유전흡수율 및 성극지수를 측정하여 전동기의 절연상태를 평 가해야 할 것으로 판단된다.

\section{감사의 글}

본 연구는 국토해양부 교통체계효율화사업의 연 구결과로 수행되었음.

\section{참고 문헌}

[1] 길경석, 송재용, 서황동, 김용주, 강동식, 황돈 하, “저압유도전동기에서 미소부분방전 측정 에 관한 연구”, 전기전자재료학회논문지, 18 권, 10호, p. 960, 2005.

[2] H. A. Toliyat, G. Suresh, and A. Abur, "Simulation of voltage stress on the inverter fed induction motor winding supplied through feeder cable", Industry Application Conference, Thirty-Second IAS Annual Meeting, IAS
'97, Vol. 1, p. 143, 1997.

[3] L. Gubbala, A. Von Jouanne, P. N. Enjeti, C. Singh, and H. A. Toliyat, "Voltage distribution in the windings of an $\mathrm{AC}$ motor subjected to high dv/dt PWM voltages", Power Electronics Specialists Conference, 1995. PESC '95, 26th Annual IEEE, Vol. 1, p. 579, 1995.

[4] Christopher J. Melhorn and Le Tang, "Transients effects of PWM drives on induction motors", IEEE Transactions on Industry Applications, Vol. 33, No. 4, p. 1065, 1997.

[5] E. Persson, "Transient effects in application of PWM inverters to induction motors", IEEE Trans on IAS, Vol. 28, p. 1095, 1992.

[6] U. Bammert and M. Beyer, "Partial discharges measured with an automated system in epoxy resin and polyethylene", IEEE Transactions on Dielectrics and Electrical Insulation, Vol. 23, No. 2, p. 215, 2000.

[7] A. Krivda, E. Gulski, L. Satish, and W. S. Zaengl, "The use of fractal features for recognition of 3-D discharge patterns", IEEE Transactions on Dielectrics and Electrical Insulation, Vol. 2, No. 5, p. 889, 1995.

[8] R. E. James and B. T. Phung, "Development of computer-based measurements and their application to PD pattern analysis", IEEE Transactions on Dielectrics and Electrical Insulation, Vol. 2, No. 5, p. 838, 1995.

[9] E. Gulski, H. P. Burger, G. H. Vailancourt, and R. Brooks, "PD pattern analysis during induced test of large power transformers", IEEE Transactions on Dielectrics and Electrical Insulation, Vol. 7, No. 1, p. 95, 2000.

[10] E. Gulski, "Diagnosis of HV components by digital PD analyzer", IEEE Transactions on Dielectrics and Electrical Insulation, Vol. 2, No. 4, p. 630, 1995.

[11] C. Cachin and H. J. Wiesmann, "PD recognition with knowledge based preprocessing and neural networks", IEEE 
Transactions on Dielectrics and Electrical Insulation, Vol. 2, No. 4, p. 578, 1995.

[12] IEEE 60043, IEEE Recommended Practice for Testing Insulation Resistance of Rotating
Machinery, p. 7, 2000.

[13] IEC 60085-1, Thermal evaluation and classification of electrical Insulation, p. 5, 1984. 